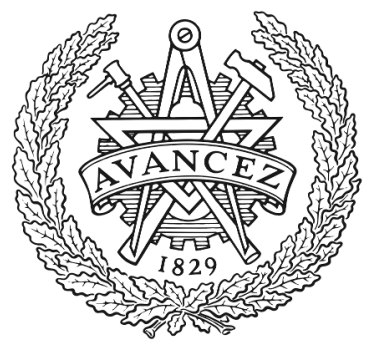

CHALMERS

UNIVERSITY OF TECHNOLOGY

\title{
Prospective study of lignin-based and recycled carbon fibers in composites through meta-analysis of life cycle assessments
}

Downloaded from: https://research.chalmers.se, 2023-04-26 01:55 UTC

Citation for the original published paper (version of record):

Hermansson, F., Janssen, M., Svanström, M. (2019). Prospective study of lignin-based and recycled carbon fibers in composites through meta-analysis of life cycle assessments. Journal of Cleaner Production, 223: 946-956. http://dx.doi.org/10.1016/j.jclepro.2019.03.022

N.B. When citing this work, cite the original published paper. 


\section{Prospective study of lignin-based and recycled carbon fibers in composites through meta-analysis of life cycle assessments}

Frida Hermansson*, Matty Janssen, Magdalena Svanström

*Corresponding author: Frida.Hermansson@chalmers.se

Division of Environmental Systems Analysis, Department of Technology Management and

Economics, Chalmers University of Technology, Gothenburg, SE-412 96, Sweden

\section{(cc) BY-NC-ND}

(C) 2019 This manuscript version is made available under the CC-BY-NC-ND 4.0 license http://creativecommons.org/licenses/by-nc-nd/4.0/ 


\section{Abstract}

Screening the life cycle assessment literature for information and recalculating extracted results was proven useful for identifying environmental challenges and opportunities in new, but related, contexts at early stages of technology development. The method was applied to carbon fiber reinforced polymers, a material of growing importance in industrial applications where a strong and/or light material is needed, such as in aircrafts and road vehicles. Many technology development efforts with the purpose of further improving such composite materials are ongoing, in particular regarding the origin of carbon fibers. Using lignin as a bio-based feedstock and various recycling techniques have been suggested. However, these technologies do not yet exist at a scale that would enable a meaningful life cycle inventory, while the need for environmental guidance is urgent in order to ensure that only the more promising development paths are pursued before lock-in occurs. With a specific focus on the shift to lignin as a feedstock for carbon fibers and on recycled carbon fibers in composites, this article not only illustrates the type of information that can be obtained from mining and refining information from earlier life cycle assessment studies, but it also provides direct guidance on environmental opportunities and challenges specific for carbon fiber reinforced polymers. Thereby, it informs both technology development efforts and environmental assessment efforts. Amongst other things, the analysis reveals that an important factor behind the environmental impact of composites is the energy demand in carbonization of the carbon fibers and that both the shift to lignin-based and to recycled carbon fibers can potentially reduce this environmental impact. However, assessments of both lignin (as an output from a multifunctional process) and recycled carbon fibers (as an output from end-of-life activities) are connected to challenges related to the allocation of environmental impacts in an environmental assessment. Extracting and refining information from the literature proved useful for the specific task but remains to be tested in other fields of emerging technologies. 


\section{Keywords}

Life Cycle Assessment, Carbon Fiber, Lignin, Composite, Bio-based, Recycling 


\section{Introduction}

Environmental assessments of technologies in early developmental stages are hampered by the low availability of relevant information. This is of particular concern because these are stages at which many important choices are made that may greatly affect the environmental performance of these technologies, choices that may even be irreversible because of a resulting lock-in by various types of investments or structures that are put in place. This is sometimes described as the Collingridge Dilemma (Collingridge, 1980). Collingridge has described a Catch-22 between information and control; impacts are difficult to predict when technology has not yet been fully developed and utilized while change becomes more difficult when the technology becomes more entrenched. In the environmental life cycle assessment (LCA) of emerging technologies, this dilemma becomes obvious, particularly when the goal is to guide technology development. Challenges of doing such prospective LCAs in general have been described by Arvidsson et al. (2018). The present article provides guidance on how to partially overcome the lack of information at early stages by mining and refining information from earlier LCAs from similar contexts. The standard formats of reviews of earlier LCAs are qualitative and/or semi-quantitative. However, efforts are also being made in the field of metaanalysis and systematic quantitative reviews, and the Journal of Industrial Ecology dedicated a special issue to the subject in 2012 (Lifset, 2012). Since then, the number of published metaanalyses of LCAs have increased significantly. Normalizing data from different studies to the same functional unit is one possible approach in meta-analysis, to identify hotspots and compare product systems. An example is the study by Archer et al. (2018) where inventory data from life cycle studies of palm oil biodiesel were normalized to per $1000 \mathrm{~kg}$. Another example is by Lorenz et al. (2019) who recalculated the functional unit of different milk production studies to per kg of "fat and protein corrected milk" to be able to compare different systems. While the present study also normalizes data from life cycle studies to the same functional unit, it differs from traditional meta-analyses as different systems are also assembled to generate an 
understanding of systems that do not yet exist in large scale. The method is applied to the cases of lignin-based and recycled carbon fibers in composites, thereby combining the cradle-to-gate system of conventional production with systems for product recycling and alternative feedstock production. The present article, therefore, provides specific guidance to both technology developers and LCA practitioners in these contexts. The article makes important contributions to both (1) a screening LCA method for emerging technologies and (2) environmental guidance to technology development in the field of lignin-based or recycled carbon fibers in composites.

Carbon fiber reinforced polymers (CFRPs) are materials of growing importance due to their light weight combined with structural strength, of which the carbon fibers are the main provider. For example, CFRPs have proven to have greater flexural strength and fatigue properties than a corresponding steel structure, while having only one third of the stiffness (Bradley et al., 1980) and $20 \%$ of the density (Matbase). Carbon fibers are produced by spinning a polymer into precursor fibers, which are then carbonized in an energy intensive process. This is followed by surface treatment of the fibers to yield the desired physical properties. When manufacturing CFRPs, a polymer matrix material and some additives are added to carbon fibers that have been arranged in the desired way, e.g. woven into a fabric. The CFRP is then formed into the desired shape by, for example, sheet molding (Das, 2011). Finally, the CFRP piece is introduced into the intended application, in which it typically provides either a lightweighting or a reinforcement function. When CFRPs are used for lightweighting, the goal is usually to reduce the energy use, as well as the related environmental impact, of the use phase (Duflou et al., 2012). When CFRPs are used for reinforcement (e.g. by prolonging the life time of a product, such as for beams in constructions) this typically does not affect the environmental impact of the use phase in the same way because there may be no maintenance needed or input of energy for operation. The life cycle environmental gain is then instead achieved by prolonged use or 
an improved functionality. The final phase of the CFRP life cycle is end-of-life. If end-of-life involves recycling the CFRP, it can potentially reduce the overall environmental impact by reducing the use of primary materials in the CFRP or in other products (Meng et al., 2018).

Although there are often environmental advantages to CFRPs compared to other materials in many applications, there is reason to look into further improvement opportunities. Major current strands of technology development include efforts to shift to bio-based or recycled materials, in line with ideas of bio-based or circular economies. Both of these options are possible for carbon fibers in composites. In particular, some current technology development efforts look into lignin (a natural polymer), or a combination of lignin and biopolymers, as feedstock for carbon fiber production (e.g. the GreenLight (2016) and LIBRE (2016) projects). Current efforts also look into recycling either the CFRP material or carbon fibers separated from the matrix material (see e.g. the work of Meng et al. (2017) and Meng et al. (2018)). However, while a considerable number of LCAs of CFRPs have, to date, been published, only one study compares lignin-based to PAN-based fibers in composites (Das (2011)), and only a few compare the use of primary with secondary carbon fibers in composites (La Rosa et al., 2016; Meng et al., 2017).

The starting point for this study was the idea that information from earlier LCA studies can be mined and refined, not only to generate an understanding of generic environmental opportunities and challenges in the field but also to generate information for new contexts that represent emerging technology paths. This could be defined as a form of meta-life cycle assessment (meta-LCA) for screening purposes. This article reports on the use of such a method to lignin-based and recycled carbon fibers in composites to shed light on environmental challenges and opportunities in early stages of technology development. 


\section{Methodology}

The approach that was applied to shed light on the environmental challenges and opportunities of lignin-based and recycled carbon fibers in composites is outlined in this section, both for the results presented in the next section to be meaningful and to guide potential future users of the method through the process. The approach was originally to be a traditional literature review, but this became an exercise in mining, recalculating and merging data from several different types of studies to accommodate for an experienced lack of information. While this study does not include any statistical analysis, it could still fall within the scope of quantitative metaanalysis as described by Lifset (2012). It is the firm belief of the authors that this method may be useful in many other contexts of early development stages in which related fields are already fairly well covered and data can be mined, refined and reassembled to provide information in a new context.

Although presented here as a fairly straightforward and sequential process, the method was highly iterative, and each new step depended on the results that emerged in the preceding step. The major steps in our method were: (1) compiling relevant published LCA studies in literature that together have sufficient coverage of the emerging technology field, and (2) mining, recalculating and assembling information from these studies to provide an understanding of environmental challenges and opportunities related to the emerging field.

\subsection{Compiling LCA studies}

This section describes the way that the literature was screened for relevant studies that presented LCA results for CFRP materials and for the new carbon fiber sources under consideration. The method aims at providing understanding in a new field that has not yet or has only sparsely been assessed before. Consequently, studies had to be found that covered different parts of the 
full life cycle of a new (conceptual) product and that could be combined to obtain sufficient coverage. For this purpose, it is desirable that several studies are available for each life cycle part so that cross-validation can be done and relevant ranges can be selected, or averages calculated, in the subsequent step of recalculating and assembling information. In the specific case described here, LCA studies from three different fields were compiled to obtain sufficient coverage and number of studies: LCA of CFRP products, of CFRP recycling and of lignin production.

Literature was collected between June 2017 and April 2018 using Google Scholar in combination with Summon (Chalmers Library, 2010) and Scopus. Initially, the aim was to find detailed (cradle-to-gate) LCAs focused on carbon fibers (to provide input to carbon fiber technology development), but it was soon discovered that the search had to be expanded to broader (cradle-to-grave) LCAs of CFRPs, which was our intended area of carbon fiber application, as no detailed cradle-to-gate LCAs of carbon fibers were found. Literature was directly excluded from further analysis when 1) the publication language was not English, and 2) the environmental impacts related to CFRPs could not be separated from other materials in the product, for instance, if impacts related to CFRP production could not be separated from the production of other parts of a vehicle. When gathering results from the initial search for LCAs of carbon fibers, interestingly, no carbon fiber product categories other than CFRPs showed up. Of the search for LCAs on CFRP products, only one study considered lignin-based carbon fibers (Das, 2011). The data collection was, therefore, extended (using the same exclusion criteria) to cover LCAs of processes in which lignin was an output product. Further, only a few studies in the initial search examined the recycling of carbon fibers. Therefore, the search was extended to include LCAs that covered only end-of-life treatment, including recycling, of CFRP. 


\subsection{Mining, recalculating and assembling information on environmental impacts}

Results from different LCAs are only rarely directly comparable due to differences in, among others, system boundaries, the type of data used and impact assessment methods. Nevertheless, in order to explore overall patterns and orders of magnitude of impacts, some reported results were selected and further treated to allow for such comparisons and for assembling to new systems. In order to determine which results to compare and how to recalculate them, 1) functional units, system boundaries, common environmental impact categories and differences between impact assessment methods, and 2) how results were presented with regard to life cycle phases in the selected literature, had to be assessed to find common denominators and methodology overlaps and differences. The mining of information was guided by particular information needs with regard to the emerging technologies. Answers to the following questions were sought:

- What is the cradle-to-grave environmental impact of today's CFRP products and of their benchmarks (i.e. what is the environmental window of opportunity for novel technologies)?

- How important is the carbon fiber cradle-to-gate impact compared to that of other constituents of the CFRP material and to other life cycle stages (i.e. is the carbon fiber cradle-to-gate impact critical or is e.g. the functionality of the fibers and the resulting material more important)?

- What gains can be achieved from recycling CFRP materials?

- How do lignin-based carbon fibers compare to traditional PAN-based carbon fibers and to recycled carbon fibers in a cradle-to-gate comparison?

Some studies contained enough information to answer one or several of these questions. The fourth question is the central question in our study as it concerns the core issue; is it interesting from an environmental perspective to produce carbon fibers for composites from lignin or to 
recycle carbon fibers for these applications, and what are the connected environmental challenges and opportunities? None of the compiled LCA studies answered this question sufficiently, and therefore, results from different studies were extracted and combined for this purpose.

When comparing employed methodologies, it became clear that only a few environmental impact categories could be selected for comparisons between several studies. Further, the different functional units employed in the compiled studies and our aim to compare across product categories and to use different system boundaries (e.g. cradle-to-grave and cradle-togate) made recalculations necessary. Only when analyzing comparisons with the conventional materials (e.g. with steel or fiberglass) presented in the studies were the original functional units of the studies fully preserved, and no recalculations were made. For other comparisons between studies shown in this article, the functional units of either one $\mathrm{kg}$ of CFRP or one $\mathrm{kg}$ of carbon fiber were employed. When needed (and if possible), results from the literature were recalculated. What is important to keep in mind is to relate the correct share of environmental impact (of either CFRP or carbon fiber) to the right mass flow (of either CFRP or carbon fiber). Compiled results were, when possible, disaggregated and reassembled into life cycle phases that allowed for finding answers to the questions listed above in this section, see Figure 1. 


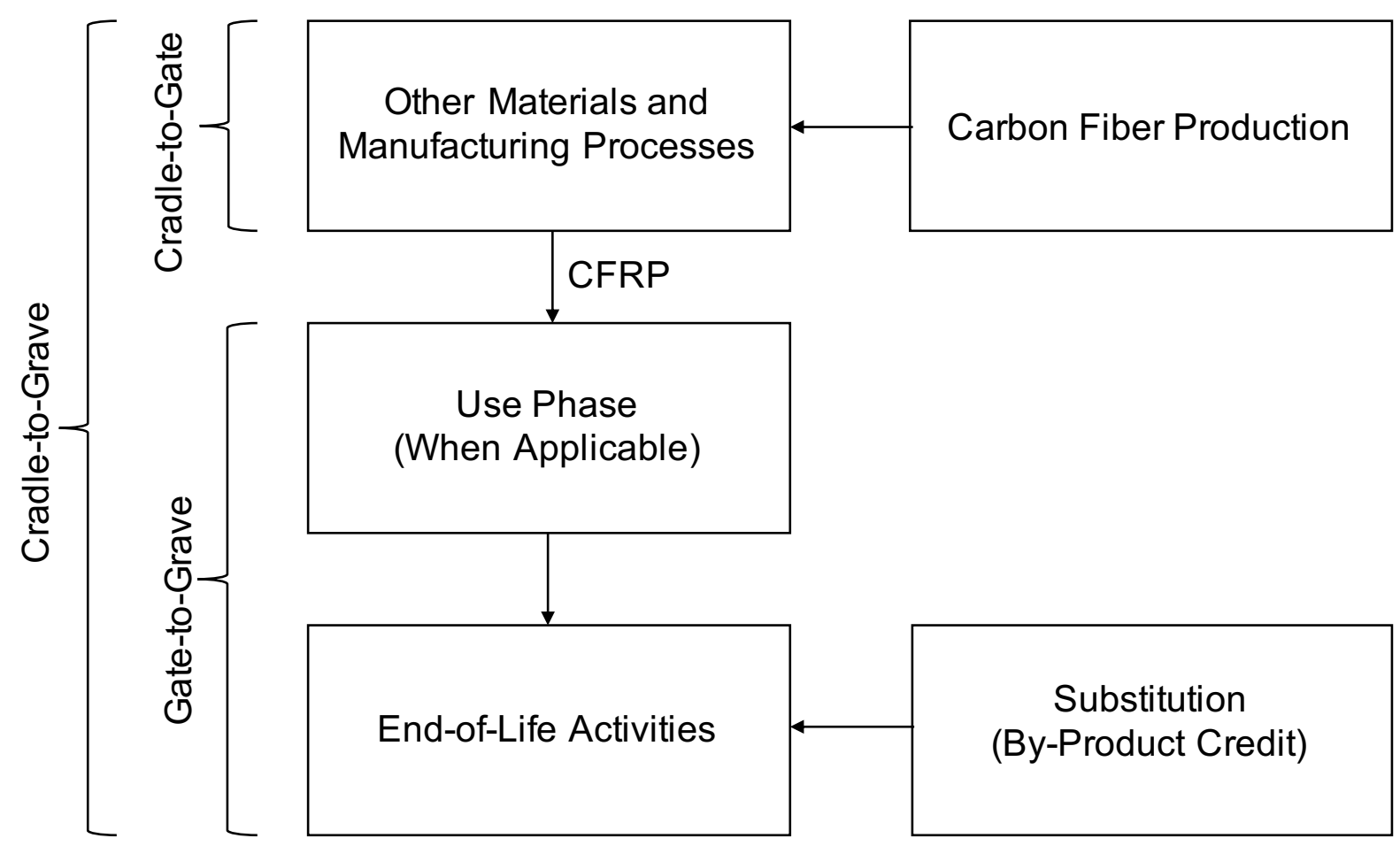

Figure 1: Simplified life cycle of CFRP products; this division is used for results presentation in this article.

Quantification of uncertainties and potential errors was only rarely touched upon in the compiled studies and was never provided in full. Further, with the relatively low number of studies and the particular scope of this study, it was not deemed meaningful to make any quantitative error or uncertainty analyses. However, variations in results between or within studies are shown herein to give an indication of the potential differences between outcomes.

\section{Results and discussion}

A total of 23 LCAs of different CFRP products were compiled. The studies were sorted into the following types of intended applications for further comparison: use of CFRPs for lightweighting (19 studies; mostly in road vehicles) or for reinforcement (four studies). An additional 13 studies covered only the end-of-life phase for non-specified applications. Further, 12 LCAs in which lignin was a product output were compiled. All references are listed in Supplementary Material. 
As the objective was to compile richer material for the novel technologies than was found in the literature, we considered it important to collect a sufficient amount of studies so that several different studies covered each life cycle stage under consideration. The particular needs of this study made it necessary to search for published studies in three different fields to find sufficient coverage. This automatically provided a adequate number of studies to allow for comparisons within some impact categories. There was no need to explore literature systematically and exhaustively for the purpose of this article, but an effort was nevertheless made to find enough to provide a rich source of information and to avoid bias.

Life cycle impact categories were selected to allow for relevant comparisons between as many studies as possible. Midpoint categories were the most common for the presentation of results in the compiled literature. Such results also allow for more consistent comparisons than endpoint level results, provided that assessment methods and other relevant assumptions are known and important differences are corrected for. The two most commonly employed midpoint categories were climate impact and energy use, and these were, consequently, selected for comparisons across studies (the frequency of applied midpoint impact categories can be found in Figure S1 in Supplementary Material). It comes as no surprise that climate impact and energy use were the most common in CFRP studies as it is often of primary relevance to verify if the reduction in energy use in the use phase leads to life cycle energy savings, and if this also leads to a reduction in climate impact. Climate impact normally correlates quite strongly with many other environmental impact categories, such as acidification, eutrophication and photochemical ozone creation (Janssen et al., 2016), which makes it a useful proxy indicator for environmental impact in general. If our method is applied to other compilations of LCA literature, other or additional impact categories could possibly be selected. However, the energy 
use and climate impact categories have hitherto been very common, and they also offer some comparability across studies, as will be discussed next.

The different studies from which results were extracted and recalculated for the comparisons did not all employ exactly the same impact assessment methods (see Tables S4, S5 and S6 in Supplementary Material for details). However, in most cases, these methods were deemed sufficiently comparable. For climate impact, all studies considered the indicator of global warming potential (GWP; cumulative radiative forcing) over a 100-year period, using characterization factors supplied by the IPCC. All studies also considered biogenic carbon dioxide to be climate neutral. This is the most commonly applied climate impact assessment method overall in LCAs (Røyne et al., 2015). In a few cases, the impact assessment method was not specified, and for those studies, a reasonable assumption is that the most common method has been used. Since the IPCC updates its GWP characterization factors regularly, some minor differences due to such changes are possible (Forster et al. (2007) and the Intergovernmental Panel on Climate Change (2014)). Except for this, any differences are attributable to the scope of the studies and to the studied technologies rather than the impact assessment methods. Impact assessment methods varied more for energy use, and more differences can be expected due to differences in impact assessment methodology than for climate impact. Typically, however, energy use was reported as non-renewable primary energy use or was unspecified. Any comparison must be interpreted in light of such differences and uncertainties. For a further discussion on different energy use indicators, see Arvidsson and Svanström (2016). 


\subsection{Comparison of CFRPs with other materials}

The first question that guided the extraction of information was how CFRPs perform compared with conventional materials. For this comparison, the system boundaries and functional units, as given in the original work, were kept to allow for comparisons between replacing conventional materials with CFRP in both lightweighting (Albrecht et al. (2013); Das (2011); Khalil (2017); Kim (2015); Overly et al. (2002); Suzuki et al. (2003); Suzuki and Takahashi (2005a); Witik (2011)) and reinforcement (Hofstätter (2017) and Zhou (2013)) applications. The intention of these comparisons was to shed light on typical orders of magnitude of the environmental challenge when CFRP material is replaced with a material containing ligninbased or recycled carbon fibers. The relative change was calculated using Equation (1):

$$
\text { Relative change }\left(X_{0}, X_{1}\right)=\frac{X_{1}-X_{0}}{X_{0}}
$$

where $X_{0}$ is the impact before the change, and $X_{I}$ is the impact after the change. In this context, $X_{0}$ is for conventional material and $X_{l}$ is for CFRP. A value of zero, consequently, represents an equal performance of conventional material and CFRP material. A negative value means that the use of CFRP decreased climate impact or energy use. The results are shown in Figure 2. 


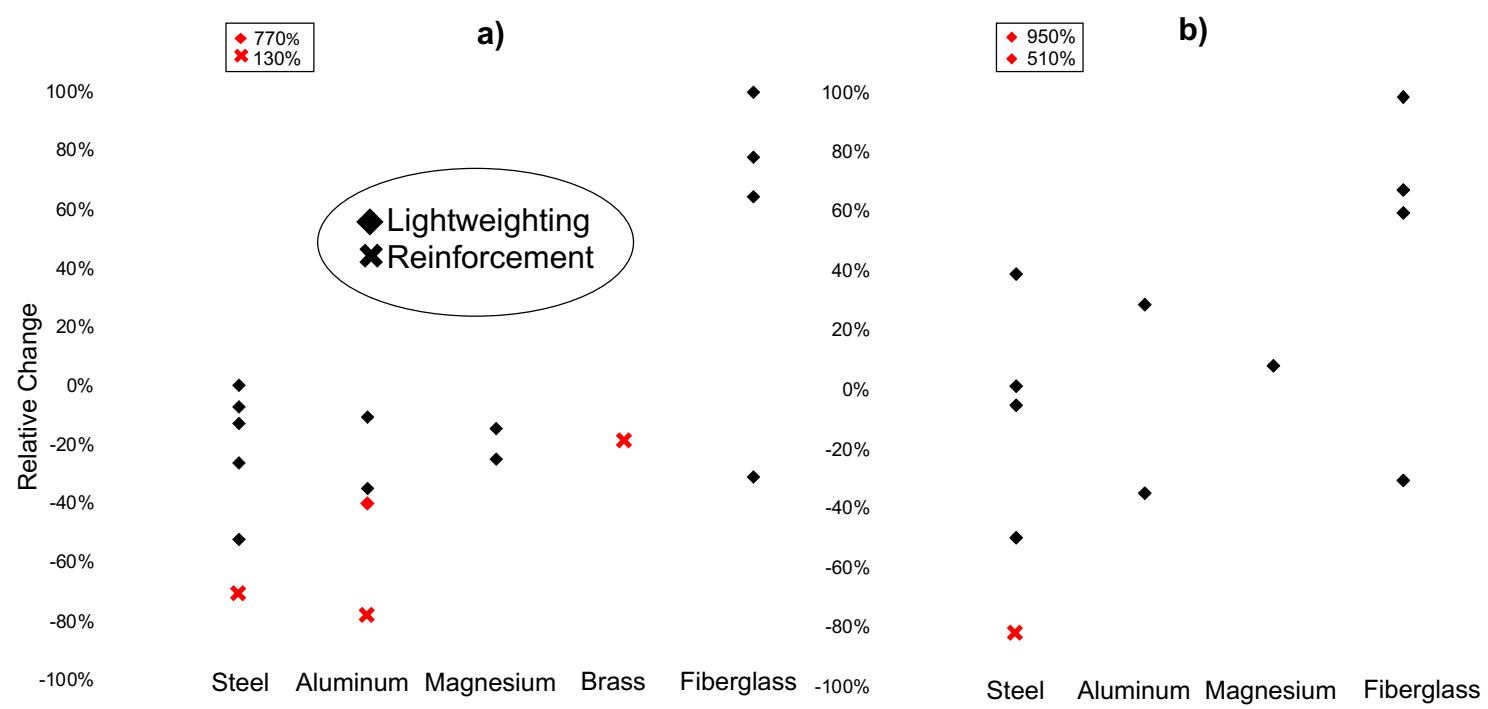

Figure 2: The relative change for (a) climate impact and (b) energy use when transitioning from conventional materials to CFRP. Only the average value is shown when there are multiple cases for the same material in the studies. Values outside the displayed range are shown in boxes on top of each graph using numbers. The red markers represent cases where the use phase was excluded.

Figure 2 presents the relative change when switching from a conventional material to a CFRP material, as presented in different studies. The use of CFRP decreased climate impact in $68 \%$ of the cases and decreased energy use in $36 \%$ of the cases (taking all scenarios in all studies under consideration, the corresponding numbers are $63 \%$ and $46 \%$, respectively).

Comparisons between studies are sometimes difficult to make because of differences in system boundaries and functional units. All the extreme outliers in Figure 2 can be explained by such differences. For the outliers in which steel was replaced for lightweighting purposes, the results were compared on a per kg basis, which punishes the heavier steel material. The use phase was also excluded in these studies so that off-sets by savings in the use phase are not visible. One other lightweighting application excluded the use phase, but in that application, the functional 
unit was based on volume (see the red hollow diamond in Figure 2a). The effect of lightweighting could be included in this way because of the difference in density. Results are also provided per $\mathrm{kg}$ of material for the steel outlier for reinforcement (130\%, see Figure 2a). The positive relative change from replacing steel with CFRP in this case is because that study does not account for the fact that less mass would be needed for a product of the same shape. This highlights the importance of selecting a relevant functional unit in relation to system boundaries when comparisons are made with a reference material. For instance, recalculating the energy use values of steel to per-volume decreased the relative change significantly, to 25$190 \%$ instead of $380-1300 \%$. Disregarding the oddities that can be explained by critical differences in methodological choices, Figure 2 shows that decreases in environmental impacts are not always substantial and, in some cases, environmental impacts increase. This result indicates that there is a general need for environmental improvement of CFRPs and that proposed bio-based or circular solutions must carefully scrutinize environmental consequences.

Comparing the different materials in Figure 2, replacing steel, aluminum, magnesium or brass with CFRP seems beneficial. The shift to CFRP from fiberglass, however, appears to lead to an increase in environmental life cycle impact because this material is already lightweight. Important factors behind the outcomes are the high energy use in carbon fiber production and differences in the assumed mileage for transport applications. Clearly, the shift to CFRP from conventional materials does not automatically generate environmental improvements, and both carbon fiber production and functionality are important factors. The following section examines the details of the CFRP life cycle environmental impact.

\subsection{Comparison between parts of the CFRP life cycle}

An analysis of how results are presented in the literature showed that it is possible, and meaningful in relation to the objectives of the present study, to divide the full life cycle of CFRPs into several parts (see Figure 1) and still be able to include results from a large number 
of the studies in the comparisons of climate impact and energy use. In this section, a division into cradle-to-gate and gate-to-grave impacts is first explored (Section 3.2.1), and then CFRP manufacturing (Section 3.2.2) and end-of-life activities (Section 3.2.3) are examined in more detail.

\subsubsection{Cradle-to-Gate vs. Gate-to-Grave impacts}

Figure 3 shows the climate impact and the energy use, respectively, of the cradle-to-gate and gate-to-grave parts of the CFRP life cycles in studies in which this information was possible to extract (references provided in Figure 3). Studies that covered only the end-of-life phase are not shown in Figure 3 but are shown later in Section 3.2.3. Note that substitutions are, when possible, shown separately from other gate-to-grave activities. Note also that all results are provided for the functional unit of $\mathrm{kg}$ of CFRP. This means that some recalculations had to be made, see Section 2.2. 


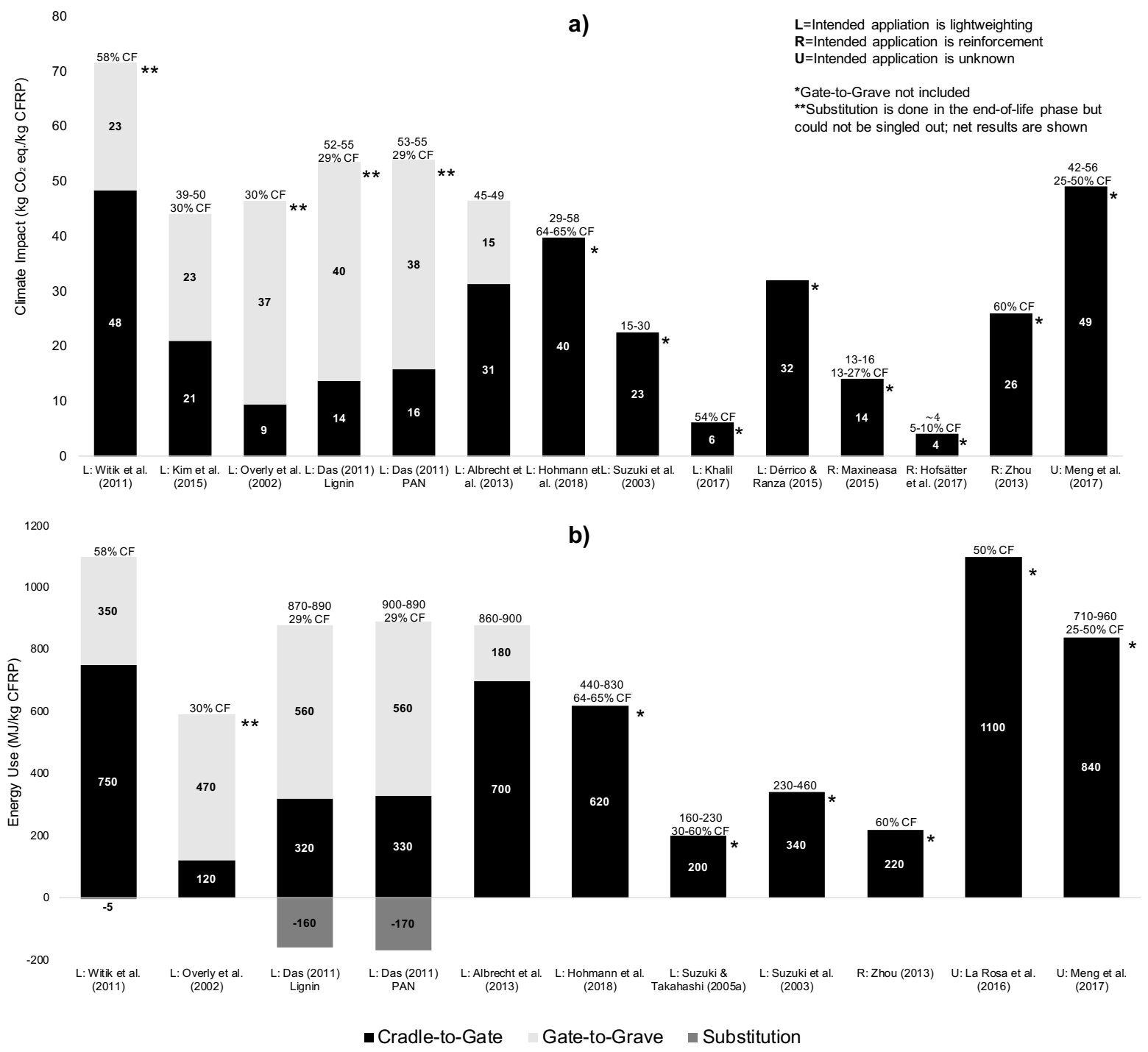

Figure 3: The life cycle (a) climate impact and (b) energy use for selected studies. Mass percentages of carbon fibers in the CFRP material are shown above each bar (when available). The numbers in the bars show the values for each part - the average value is depicted - and total ranges for the full life cycle (or displayed part) are provided on top of each bar when the studies include multiple cases, but without the credits from substitution. Substitutions done for by-product credits in end-of-life processes are shown separately when possible. 
Figure 3 shows that, in the studies in which full cradle-to-grave information was available (these were all lightweighting applications), the cradle-to-gate part contributed significantly (from about $20 \%$ to $70 \%$ ) to the total life cycle impact for both climate impact and energy use. In these studies, the large impact from the use phase was the very reason for the shift to CFRPs from other heavier materials. However, with the relative environmental improvement of the use phase that comes with the shift, the material production instead stands out as an important opportunity for further environmental improvements. The differences in climate impact and energy use related to the use phase can partly be attributed to differences in mileage (i.e., distance driven) and in transported mass. The longer the distance a vehicle is driven and the more mass it carries over this distance, the lower the impact from other parts of the life cycle that are attributed to each unit of distance and carried mass. In Figure 3, where results are shown per $\mathrm{kg}$ of CFRP, a higher assumed mileage than in the original study would result in a greater impact for the gate-to-grave part and thus a lower contribution from the cradle-to-gate part relative to other parts of the life cycle because these would remain the same. When assessing the potential of CFRPs in lightweighting applications, it is reasonable to include the use phase within the system boundaries, and it is highly important to select a functional unit that reflects the function and the performance of the material in the actual product in a relevant way. The most common functional unit was a certain mass in the few studies that investigated the use of CFRPs for reinforcement, and these studies only included the cradle-to-gate part. Figure 3 shows that the magnitude of cradle-to-gate impacts for these applications per kg of CFRP are in the same range as the lightweighting applications.

It can be hypothesized that a higher content of carbon fibers in a material leads to a stronger and more durable material so that it can be used in more demanding applications or an increase in the life time of the product. Further, as carbon fiber production has been shown in earlier 
studies to give rise to a large environmental impact (Das, 2011), it can also be expected that a larger share of carbon fibers will increase the impacts per $\mathrm{kg}$ from the cradle-to-gate part. A CFRP with a high content of carbon fibers can, therefore, be expected to have a greater impact from materials production, and the relative contribution of materials production to the total life cycle impact would be expected to be greater. However, an examination of the results in Figure 3 shows that at this level it is not possible to find strong support for this.

\subsubsection{CFRP Manufacturing}

Figure 4 shows the cradle-to-gate climate impact and energy use, respectively, per kg of CFRP produced in the compiled studies. The cradle-to-gate results in Figure 4 are divided into (1) the carbon fiber cradle-to-gate impact, and (2) other materials' cradle-to-gate impact (including polymers, additives and transports) and impacts from CFRP manufacturing processes (including, e.g. shaping and molding) (see Figure 1). 


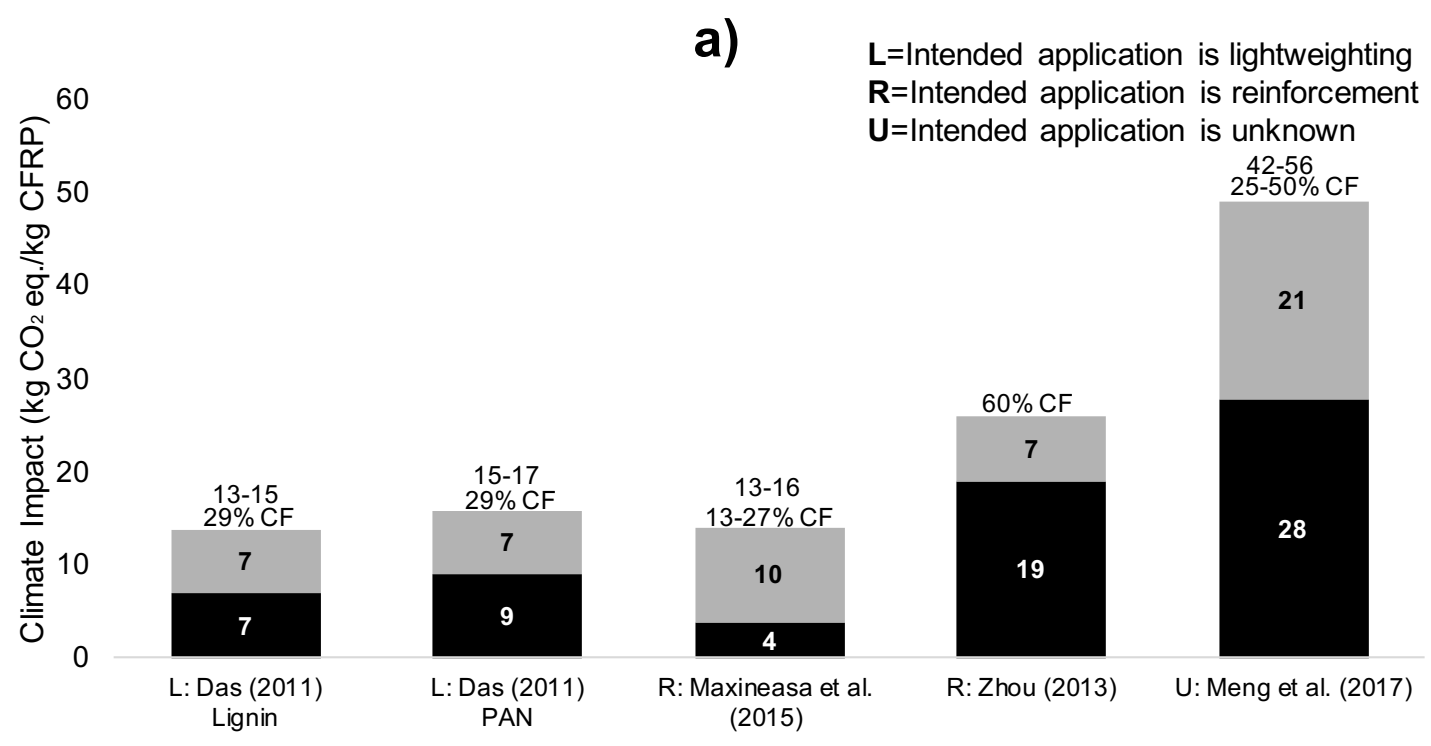

b)

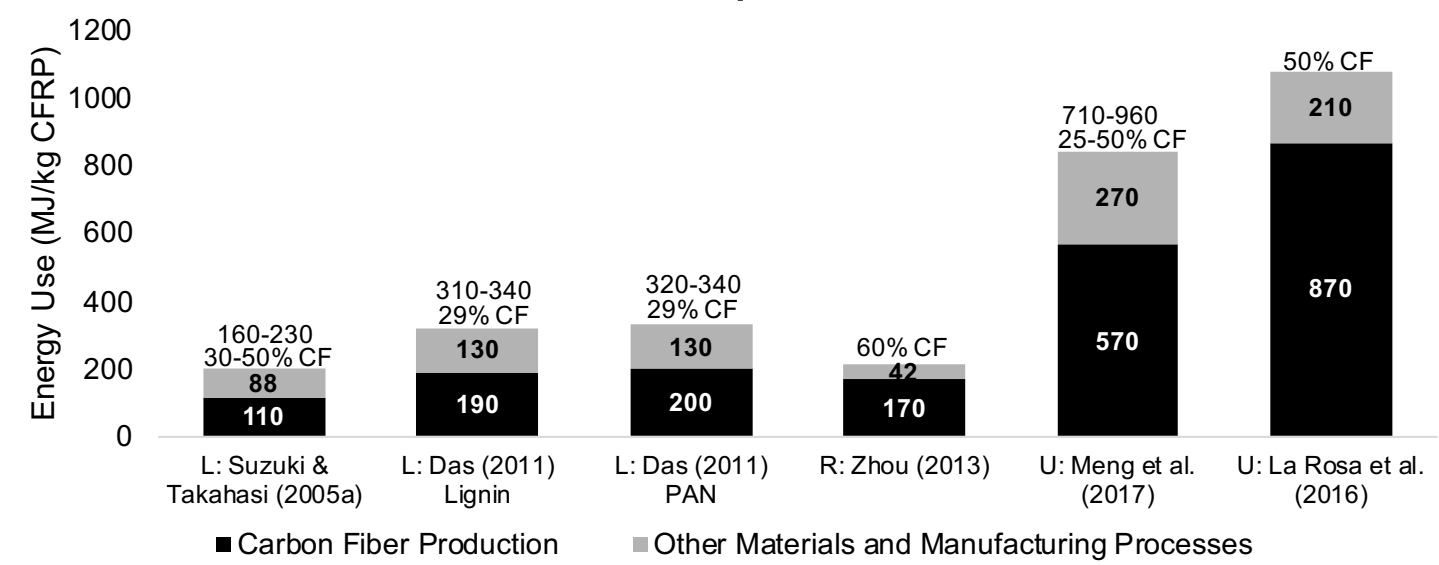

Figure 4: The (a) climate impact and (b) energy use of the cradle-to-gate part of the CFRP life cycle. Mass percentages of carbon fibers in the CFRP material are shown above each bar (when available). The numbers in the bars show the values for each part; the average value is displayed for studies that include multiple cases, and the total range for the cradle-to-gate impact for all cases in that study is shown in numbers above the bar.

Figure 4 shows that the impact of carbon fiber alone contributes to at least half of the total cradle-to-gate climate impact for all studies but one (Maxineasa et al., 2015). In that study, the carbon fiber content was significantly lower than in the other ones. Furthermore, carbon fiber was found to contribute significantly more than $50 \%$ to the cradle-to-grave life cycle energy 
use in all studies. This can be explained by the considerable environmental impact and energy use of the massive demand for energy (and associated emissions) for converting the precursor fiber into a carbon fiber. It is, therefore, important to focus on the environmental performance of carbon fiber in further technical development.

\subsubsection{End-of-Life Activities}

Studies that were found to deal exclusively with the end-of-life of CFRP (including recycling) are shown in Figure 5. 


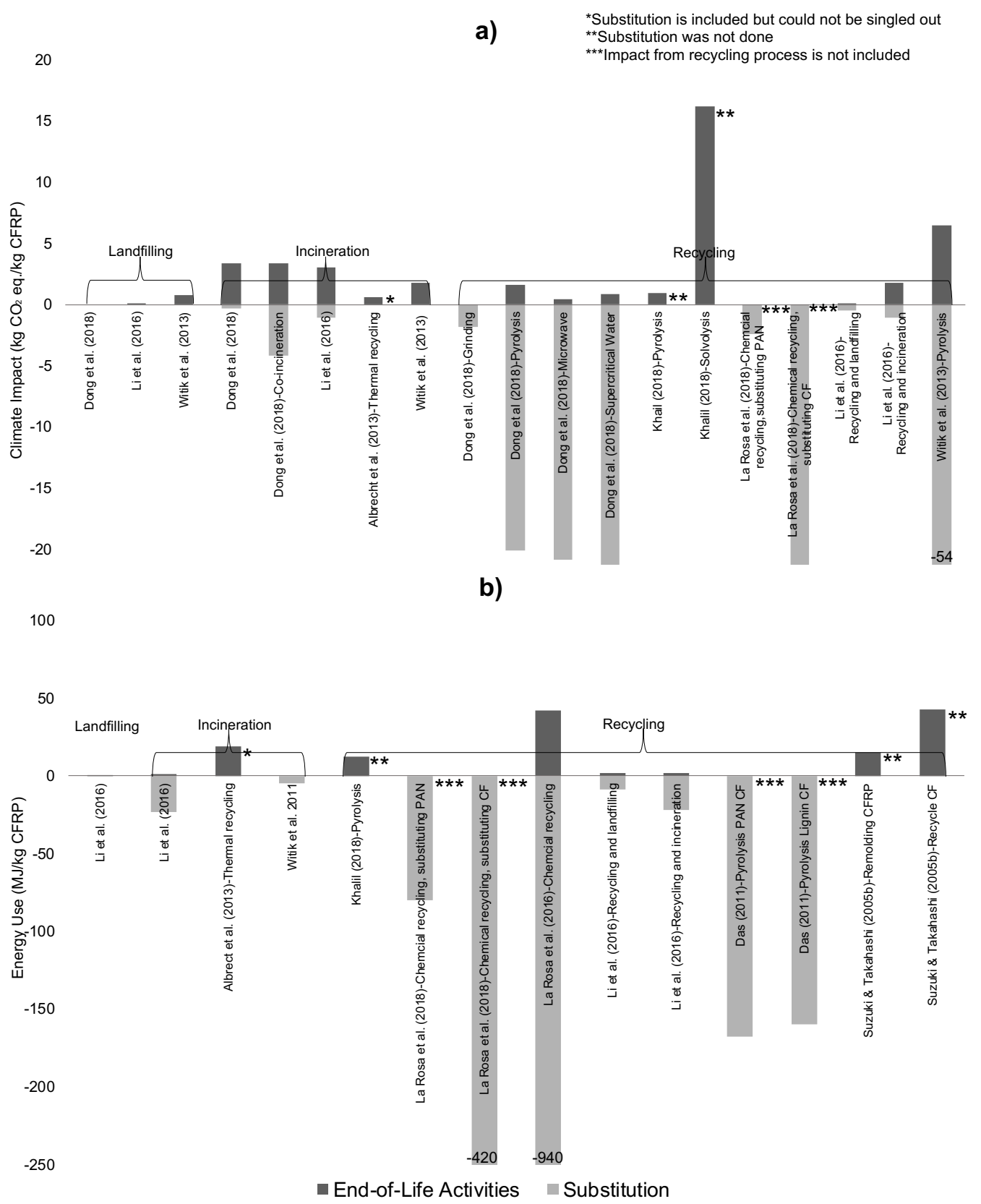

Figure 5: Climate impact (a) and energy use (b) for different end-of-life activities for CFRP.

One of the studies presents an average of four values but for the same type of end-of-life activity (Albrecht et al., 2013). Note that the Y-axis has been cut off for some studies. The full value is stated at the end of the bar for those studies. 
When end-of-life activities were found to lead to new products, e.g. heat and/or electricity from incineration or a recycled material, this was managed methodologically by means of substitution, i.e., the product was assumed to replace a conventional alternative product, and the studied product was given a credit for avoided resources and emissions related to this alternative product. There were large variations in the size of the substitution in the compiled studies, in particular for recycling. This is because of the type of product the recycled carbon fiber was considered to replace. For example, Li et al. (2016) applied mechanical recycling to CFRP, yielding a recycled carbon fiber that could replace glass fibers, and therefore applied a credit corresponding to the production impact of glass fibers (lower than for carbon fibers). If the recycled carbon fiber could replace virgin carbon fiber, the credit would likely be larger if the same approach is used.

Landfilling typically had the lowest impact in a comparison of the different end-of-life technologies alone, followed by incineration and recycling. When substitutions were considered, it was the opposite, which often resulted in considerable savings for the recycling option. It is clear that recycling of lignin carbon fibers is interesting from an environmental perspective, provided that a sufficient quality can be achieved.

\subsection{Assessing possible product development options: Lignin-based carbon fibers and recycling of carbon fibers}

In Sections 3.2.1 and 3.2.2, it was pointed out that the part representing the largest share of life cycle environmental impact was generally the cradle-to-gate phase, and carbon fiber production was generally responsible for the main part of this impact. In particular, the carbonization of PAN fiber is highly energy intensive (treatment at $1000-1700{ }^{\circ} \mathrm{C}$ for $0.5-2$ hours (Das, 2011)). Using lignin as a precursor material for carbon fibers would, at least in theory, reduce the energy use in carbonization because of the relatively high content of aromatics and of oxygen in lignin that would facilitate carbonization and thermo-stabilization, respectively (Das, 2011). The 
higher content of carbon in lignin would also, in principle, increase yields. Using lignin would also entail other benefits associated with a transition from a fossil-based to a bio-based economy, as well as lower the cost and avoidance of emissions of hydrogen cyanide (Das, 2011). The environmental consequences of a shift to lignin in precursor fibers is assessed in more detail in Section 3.3.1 using a method that combines information on CFRPs and lignin production from different groups of LCA studies.

The environmental impacts related to the carbon fiber may also be decreased by using recycled carbon fibers in CFRP because impacts from primary carbon fiber production would then be avoided. However, this requires that the recycling is done with moderate environmental impacts and with sufficient yield and preservation of the structural properties of the fiber. Environmental impacts of a shift to recycled carbon fibers are considered in more detail in Section 3.3.2, combining information from LCA studies on CFRP products and CFRP recycling. Figure 6 shows the compiled results for both a shift to lignin and a shift to recycled carbon fibers.

\subsubsection{Switching from PAN to Lignin}

Only one CFRP LCA study in the compiled literature included a lignin-based precursor fiber (Das, 2011). Therefore, we searched for additional studies that could provide information on the environmental impact of lignin production. Lignin is not a main product of any process, but it appears as a by-product of several different processes.

Figure 6 displays the life cycle climate impact and energy use of cradle-to-gate carbon fiber production found in the literature. These impacts are shown as per kg of carbon fiber for PANbased fibers (the first set of values on the x-axes) and lignin-based fibers (the second set on the $\mathrm{x}$-axes). 

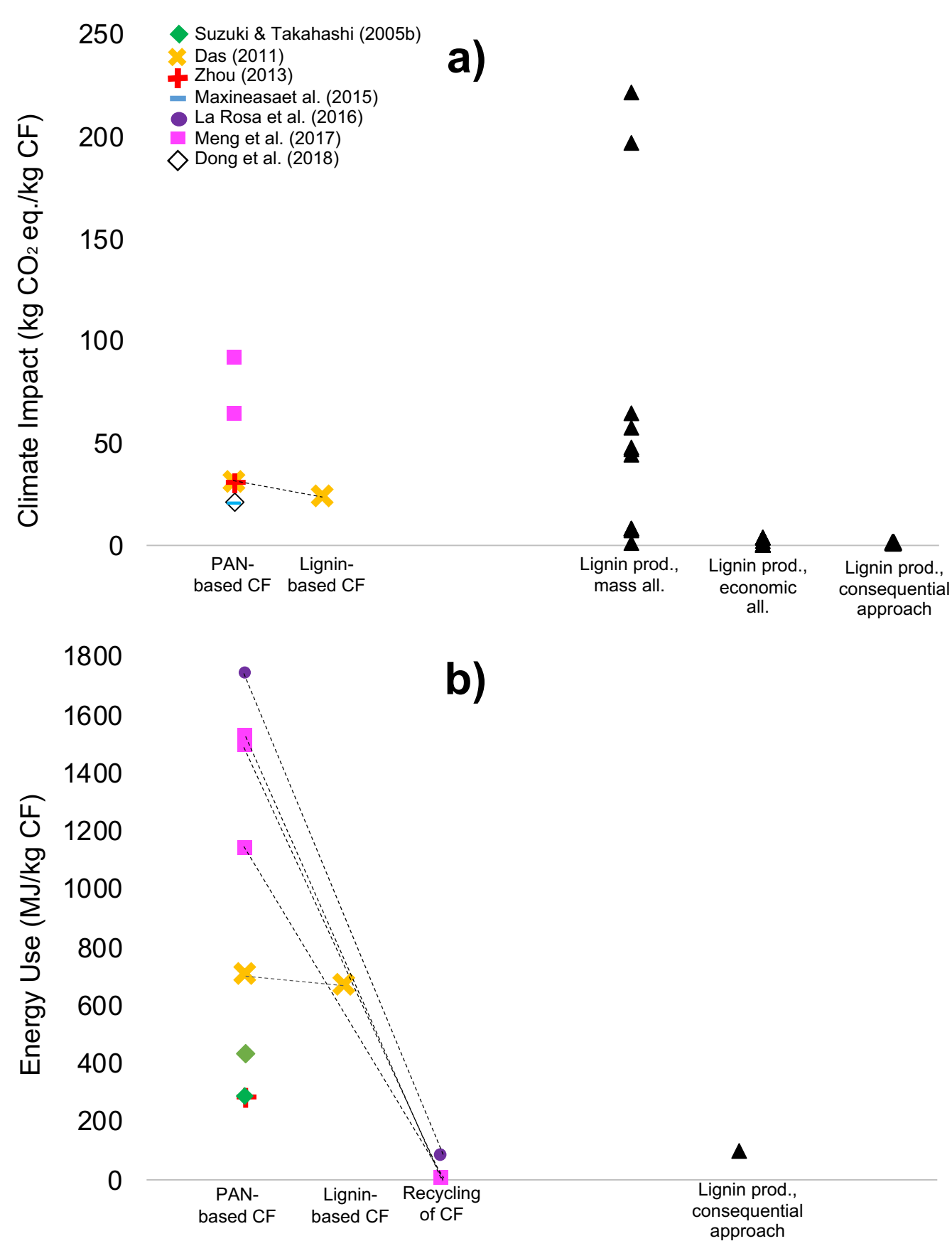

Figure 6: Climate impact (a) and energy use (b) for primary carbon fiber production (PANand lignin-based, respectively, for all available scenarios in all studies), and energy use for secondary (recycled) carbon fiber production. The values on the right-hand sides are the climate impact and energy use of lignin production for the amount needed to produce $1 \mathrm{~kg}$ of carbon fiber (assuming $2 \mathrm{~kg}$ lignin) using two different allocation methods and one consequential approach. 
The shift to lignin in the study by Das (2011)resulted in an improvement of both climate impact and energy use (see the dashed lines connecting the yellow data points in Figure 6). The gains in climate impact attributable to the shift to lignin are related to the larger share of biomass energy in the life cycle of lignin than in the life cycle of PAN-based carbon fibers. Das (2011) used mass allocation to give an impact to lignin from the plant where it was liberated and assumed the same energy use for carbonization as for a PAN-based precursor fiber.

Figure 6 (right-hand side of the graphs) contains data for lignin production from seven different studies on lignin-generating processes (Bernier et al. (2013); Culbertson et al. (2016); do Nascimento et al. (2016); González-García et al. (2017); González-García et al. (2016); González-García et al. (2011); Gullón et al. (2018)). It has to be noted that these values represent only the first part of the carbon fiber life cycle and should be combined with data for the subsequent processing of lignin into carbon fiber to be comparable to the values generated by Das (2011). If the numbers from Das (2011) are assumed to be representative, $460 \mathrm{MJ}$ (and the corresponding amount of $\mathrm{CO}_{2}$ eq. from electricity) must be added in order for their values to represent cradle-to-gate carbon fiber production; however, Das (2011) noted that the energy use in the carbonization step could be as much as $25 \%$ lower for lignin than for PAN, which would reduce this number. We here used three different methods for allocating an environmental impact from the involved activities to lignin, represented by the different sets of values in Figure 6; the same economic data were applied to all studies in the economic allocation $(0.3 € / \mathrm{kg}$ of lignin and $0.73 € / \mathrm{kg}$ pulp, see Table S3 in Supplementary Material for details and prices of other co-products), and the mass outputs in each individual study were used for mass allocation (see Supplementary Material-Calculations for more information). In the so-called consequential approach, the extracted lignin that would have to be replaced by the 
corresponding energy content of natural gas was considered because this is what would happen in some contexts if lignin was removed from the pulp mill (Bernier et al., 2013). Further, it was assumed in the calculations for Figure 6 that the precursor fibers consisted of lignin only and that the yield in the subsequent carbon fiber production would be $50 \%$. In reality, additives or other polymers may be mixed into the precursor fiber, which influences the life cycle environmental impact of the fiber (Das, 2011). Figure 6 shows that the outcome of a shift to lignin highly depends on how large an environmental impact is allocated to lignin from processes earlier in its life cycle. Das (2011) discussed some contexts in which it would be reasonable to consider lignin as a by-product free of environmental burden (e.g. in pulp production). Replacing PAN with lignin as a precursor material using the economic allocation for outputs from the lignin-generating process gives a lower impact to lignin than when mass allocation or a consequential approach is applied. This is because of the, sometimes, very high mass output of lignin compared to other outputs from the lignin producing process (from $2 \%$ to $48 \%$ ) and that the consequential approach assumes that lignin output is replaced by natural gas. The relatively low market price of lignin leads to a low allocation factor when using economic allocation (from $0 \%$ to $5 \%$ ). This result highlights the importance of the choice of allocation method, or marginal energy source, for the consequential approach. A problem is that the market for lignin is not yet mature, and different uses of lignin are only starting to be explored. Lignin market prices may change and vary in the future due to, e.g. the presence (or lack) of competing uses for lignin, or policy instruments.

\subsubsection{Using Recycled Carbon Fibers}

Another possible path for decreasing the environmental impact of CFRPs would be to use recycled carbon fibers (either in CFRPs or in other products) as presented in Figure 5 and further explored in Figure 6. Figure 6 contains two data points for the energy use of recycling carbon fibers, as obtained from the studies by La Rosa et al. (2016) and Meng et al. (2017), which show that the recycling of carbon fibers could decrease energy use significantly (see the dashed 
line for recycling in Figure 6 that connects the purple and magenta data points from the same studies). However, these data points need to be considered with care. La Rosa et al. (2016) have examined thermoset recycling by means of chemicals, and Meng et al. (2017) have examined the recycling of CFRPs using a fluidized bed. Neither of these methods are by any means mature processes compared to the primary production of PAN-based carbon fibers. This implies that a reduction in energy use may be possible in the future as recycling methods are improved. Further, allocation problems also appear in material recycling because it must be determined where to draw the line between primary and secondary life cycles, and/or how to divide impacts from different processes between different life cycles. The comparison shown in Figure 6 considers only the recycling process itself to allow for a rough comparison that illustrates a potential.

\subsubsection{Comparing the two paths}

In principle, if done wisely, it would be possible to use the values presented in Figures 3-6, as building blocks to obtain an understanding of the potential environmental impact of different paths. However, to avoid that simplified conclusions are drawn, we have avoided to do this here and instead preserve the diversity and discuss conclusions that can be drawn.

Figure 6 indicates that recycling may be a very promising path for decreasing impacts related to carbon fibers and CFRP, possibly even more promising than a shift to lignin; the two approaches could potentially also be combined so that lignin is used as a make-up feedstock flow for whatever is lost in recycling or to serve an increased market demand. Recycling requires that carbon fibers can be extracted from discarded CFRP products and that secondary carbon fibers have sufficient quality for the secondary product. It is too soon to judge to what extent closed-loop recycling can be achieved and what open-loop recycling options are of interest. Also for lignin production, there are major uncertainties as lignin extraction technology is still fairly young and generated volumes are modest. As pointed out before, both options also 
require that the allocation problem is considered and the choice of allocation method may in some cases determine the outcome of the comparison rather than inherent properties of the technologies themselves.

\subsection{Discussion of method}

The employed method made it possible to understand the environmental challenges and opportunities of a shift from PAN-based carbon fibers to lignin-based or recycled carbon fibers in composites. If this method is used in other studies to provide information for emerging technologies, the amount and resolution of information available in the compiled literature will determine exactly how information from studies on different fields of technology can be compiled and if it is possible at all

Applying this method in our context gives rise to questions on how to handle allocation, especially when an economic approach is used for new products on an emerging market. Both the use of a material in several life cycles (as in recycled carbon fibers) and the use of one of several outputs from a multi-output process (as in lignin for carbon fibers), inevitably require some kind of allocation of impacts between life cycles or processes, which is a common methodological challenge in LCA (Baumann and Tillman (2004). The choice of allocation method often has a strong influence on results (as shown in Figure 6), but any differences in results will then not be related to aspects inherent to the technologies themselves but rather to methodological choices that cannot be avoided. This may make results challenging to communicate and to use in a technology development context. In other contexts, issues other than allocation may surface.

The employed method does not include any sensitivity analysis or statistical analysis. In fact, the extracted information does not allow for such analyses. The reason for this is the aggregated 
and, in some cases, opaque nature of the results found in the literature and the large differences in system boundaries along with the low number of studies found. This is a drawback of mining results from LCA literature, as the data quality is most often not discussed in detail in compiled studies, and important choices with regard to scope and system boundaries may not be provided. Therefore, it is important to compile results from several different studies to capture important variations. A sense of orders of magnitudes and possible variations can be achieved by showing all results and discussing them instead of generating mean value.

\section{Conclusions}

Extracting LCA results from earlier studies of different fields of technology and compiling them to provide an understanding of, as yet, only moderately explored fields showed that both the shift to lignin as a source for carbon fibers and the recycling of carbon fibers from discarded CFRP products can potentially result in lower environmental impact than current CFRPs. This is promising as the shift to CFRP from other materials does not, in itself, automatically generate environmental improvements; replacing conventional material with CFRP increases life cycle energy use in more than half of the cases. The production of CFRP represents a considerable share of the environmental impact also in lightweighting applications where the use phase is known to be important (at least $20 \%$ of the cradle-to-grave climate impact and energy use in the compiled studies). One important reason behind this is that the energy use in carbonization is high; carbon fiber production is responsible for more than $50 \%$ of the CFRP climate impact and energy use in all studies but one. An important factor behind the large relative importance attributed to the CFRP cradle-to-grave is the assumed functionality of the material; if the lifetime or efficiency of the material can be increased, the impact form materials production can be diluted over more service units if that is reflected in the functional unit. It also means that it is important to maintain a high functionality when shifting to other carbon fiber feedstocks. While the shift to recycled carbon fibers appears more promising than the shift to 
lignin for decreasing the environmental impacts of CFRP, both have the potential to lower the environmental impact of CFRPs and both are in line with major sustainability transition ideas - a biobased and circular economy. Further, the two strategies can be combined.

Both technological paths (using lignin as a precursor and using recycled carbon fibers) are quite young and unexplored, and large uncertainties remain about data representing large-scale production, the quality of the fibers and the market. A major challenge is, therefore, the need for allocation, both for the multifunctional process delivering lignin and for the recycling of carbon fibers, as environmental impacts of some processes inevitably must be shared between product flows or life cycles. Nevertheless, this study showed that replacing the carbon fiber raw material PAN with lignin could decrease both energy use and the climate impact of carbon fiber and recycling the carbon fiber could significantly decrease energy use. Consequently, continued research into both of these options is recommended, both in terms of the technologies as such and in terms of their environmental performance.

\section{Acknowledgements}

This study was conducted out as a part of the LIBRE (Lignin Based Carbon Fibres for Composites) project, which has received funding from the Bio-Based Industries Joint Undertaking under the European Union's Horizon 2020 research and innovation program under grant agreement No 720707. 


\section{References}

Albrecht, M., Baumann, C. P., Brandstetter, R., Horn, H. K., M. , Fischer, \& Ilg, R. (2013). Environmental Aspects of Lightweight Construction in Mobility and Manufacturing Green Design, Materials and Manufacturing Processes (1st ed., pp. 185-190). London: Taylor \& Francis Group.

Archer, S. A., Murphy, R. J., \& Steinberger-Wilckens, R. (2018). Methodological analysis of palm oil biodiesel life cycle studies. Renewable and Sustainable Energy Reviews, 94, 694-704. doi:doi.org/10.1016/j.rser.2018.05.066

Arvidsson, R., \& Svanström, M. (2016). A framework for energy use indicators and their reporting in life cycle assessment. Integrated environmental assessment and management, 12(3), 429-436. doi:10.1002/ieam.1735

Arvidsson, R., Tillman, A. M., Sandén, B. A., Janssen, M., Nordelöf, A., Kushnir, D., \& Molander, S. (2018). Environmental Assessment of Emerging Technologies:

Recommendations for Prospective LCA. Journal of industrial ecology, 22(6), 12861294. doi:10.1111/jiec.12690

Baumann, H., \& Tillman, A.-M. (2004). The Hitch Hiker's Guide to LCA. An orientation in life cycle assessment methodology and application: External organization.

Bernier, E., Lavigne, C., \& Robidoux, P. Y. (2013). Life cycle assessment of kraft lignin for polymer applications. The International Journal of Life Cycle Assessment, 18(2), 520528. doi:10.1007/s11367-012-0503-y

Bradley, J., Hastings, G. W., \& Johnson-Nurse, C. (1980). Carbon fibre reinforced epoxy as a high strength, low modulus material for internal fixation plates. Biomaterials, 1(1), 3840. doi:10.1016/0142-9612(80)90057-5

Chalmers Library. (2010). Summon Chalmers (online): Gothenburg: Chalmers Library, 2010-. Collingridge, D. (1980). The social control of technology: St. Martin's Press. 
Culbertson, C., Treasure, T., Venditti, R., Jameel, H., \& Gonzalez, R. (2016). Life Cycle Assessment of lignin extraction in a softwood kraft pulp mill. Nordic Pulp \& Paper Research Journal, 31(1), 30-U247. doi:10.3183/npprj-2016-31-01-p030-040

D'Errico, F., \& Ranza, L. (2015). Comparative environmental benefits of lightweight design in the automotive sector: The case study of recycled magnesium against CFRP and steel. In M. V. Manuel, A. Singh, M. Alderman, \& N. R. Neelameggham (Eds.), Magnesium Technology 2015 (pp. 73-78). Cham: Springer International Publishing.

Das, S. (2011). Life cycle assessment of carbon fiber-reinforced polymer composites. The International Journal of Life Cycle Assessment, 16(3), 268-282. doi:10.1007/s11367011-0264-Z

do Nascimento, D. M., Dias, A. F., de Araújo Junior, C. P., de Freitas Rosa, M., Morais, J. P. S., \& de Figueirêdo, M. C. B. (2016). A comprehensive approach for obtaining cellulose nanocrystal from coconut fiber. Part II: environmental assessment of technological pathways. Industrial Crops and Products, 93, 58-65. doi:10.1016/j.indcrop.2016.02.063

Dong, P. A. V., Azzaro-Pantel, C., \& Cadene, A.-L. (2018). Economic and environmental assessment of recovery and disposal pathways for CFRP waste management. Resources, Conservation and Recycling, 133, 63-75. doi:10.1016/j.resconrec.2018.01.024

Duflou, J. R., Deng, Y., Van Acker, K., \& Dewulf, W. (2012). Do fiber-reinforced polymer composites provide environmentally benign alternatives? A life-cycle-assessment-based study. MRS Bulletin, 37(04), 374-382. doi:10.1557/mrs.2012.33

Forster, P., Ramaswamy, V., Artaxo, P., Berntsen, T., Betts, R., Fahey, D. W., . . Myhre, G. (2007). Changes in atmospheric constituents and in radiative forcing. Chapter 2 Climate Change 2007. The Physical Science Basis. 
González-García, S., Gullón, B., \& Moreira, M. T. (2017). Environmental assessment of biorefinery processes for the valorization of lignocellulosic wastes into oligosaccharides. Journal of Cleaner Production. doi:10.1016/j.jclepro.2017.02.164 González-García, S., Gullón, B., Rivas, S., Feijoo, G., \& Moreira, M. T. (2016).

Environmental performance of biomass refining into high-added value compounds. Journal of Cleaner Production, 120, 170-180. doi:10.1016/j.jclepro.2016.02.015

González-García, S., Hospido, A., Agnemo, R., Svensson, P., Selling, E., Moreira, M. T., \& Feijoo, G. (2011). Environmental life cycle assessment of a Swedish dissolving pulp mill integrated biorefinery. Journal of industrial ecology, 15(4), 568-583. doi:10.1111/j.1530-9290.2011.00354.x

GreenLight. (2016). GreenLight-Cost effective lignin-based carbon fibres for innovative light-weight applications. Retrieved from https://greenlight-project.eu

Gullón, P., Gullón, B., Dávila, I., Labidi, J., \& Gonzalez-Garcia, S. (2018). Comparative environmental Life Cycle Assessment of integral revalorization of vine shoots from a biorefinery perspective. Science of The Total Environment, 624, 225-240. doi:10.1016/j.scitotenv .2017 .12 .036

Hofstätter, T. B., N; Mischkot, M; Stotz, P.M; Pedersen, D.B; Tosello, G; Hansen, H.N. (2017). Effects of carbon fibres on the life cycle assessment of additively manufactured injection moulding inserts for rapid prototyping. Paper presented at the Joint Special Interest Group meeting between euspen and ASPE Dimensional Accuracy and Surface Finish in Additive Manufacturing, Leuven, Belgium.

Hohmann, A., Albrecht, S., Lindner, J. P., Voringer, B., Wehner, D., Drechsler, K., \& Leistner, P. (2018). Resource efficiency and environmental impact of fiber reinforced plastic processing technologies. Production Engineering, 1-13. doi:10.1007/s11740018-0802-7 
Intergovernmental Panel on Climate Change. (2014). Anthropogenic and natural radiative forcing Climate Change 2013 - The Physical Science Basis: Working Group I Contribution to the Fifth Assessment Report of the Intergovernmental Panel on Climate Change (Vol. 423, pp. 659-740). Cambridge: Cambridge University Press.

Janssen, M., Xiros, C., \& Tillman, A.-M. (2016). Life cycle impacts of ethanol production from spruce wood chips under high-gravity conditions. Biotechnology for biofuels, 9(1), 53. doi:10.1186/s13068-016-0468-3

Khalil, Y. (2018). Comparative environmental and human health evaluations of thermolysis and solvolysis recycling technologies of carbon fiber reinforced polymer waste. Waste Management. doi:10.1016/j.wasman.2018.03.026

Khalil, Y. F. (2017). Eco-efficient lightweight carbon-fiber reinforced polymer for environmentally greener commercial aviation industry. Sustainable Production and Consumption. doi:10.1016/j.spc.2017.05.004

Kim, H. C., Wallington, T. J., Sullivan, J. L., Keoleian, G. A. (2015). Life Cycle Assessment of Vehicle Lightweighting: Novel Mathematical Methods to Estimate Use-Phase Fuel Consumption. ENVIRONMENTAL SCIENCE \& TECHNOLOGY, 49(16), 10209-10216. doi:10.1021/acs.est.5b01655

La Rosa, A., Banatao, D., Pastine, S., Latteri, A., \& Cicala, G. (2016). Recycling treatment of carbon fibre/epoxy composites: Materials recovery and characterization and environmental impacts through life cycle assessment. Composites Part B: Engineering, 104, 17-25. doi:10.1016/j.compositesb.2016.08.015

La Rosa, A. D., Blanco, I., Banatao, D. R., Pastine, S. J., Björklund, A., \& Cicala, G. (2018). Innovative Chemical Process for Recycling Thermosets Cured with Recyclamines ${ }^{\circledR}$ by Converting Bio-Epoxy Composites in Reusable Thermoplastic-An LCA Study. Materials, 11(3), 353. doi:10.3390/ma11030353 
Li, X., Bai, R., \& McKechnie, J. (2016). Environmental and financial performance of mechanical recycling of carbon fibre reinforced polymers and comparison with conventional disposal routes. Journal of Cleaner Production, 127, 451-460. doi:10.1016/j.jclepro.2016.03.139

LIBRE. (2016). LIBRE-Lignin Based Carbon Fibres for Composites. Retrieved from http://libre2020.eu

Lifset, R. (2012). Toward Meta-Analysis in Life Cycle Assessment. Journal of industrial ecology, 16, S1-S2. doi:10.1111/j.1530-9290.2012.00473.x

Lorenz, H., Reinsch, T., Hess, S., \& Taube, F. (2019). Is low-input dairy farming more climate friendly? A meta-analysis of the carbon footprints of different production systems. Journal of Cleaner Production, 211, 161-170. doi:doi.org/10.1016/j.jclepro.2018.11.113

Matbase. Stainless Steel Material Characterization. Retrieved from https://www.matbase.com/material-categories/metals/ferrous-metals/steel/highalloy/stainless-steel/material-properties-of-gx12cr14-mart-ca-15.html\#general

Maxineasa, S. G., Taranu, N., Bejan, L., Isopescu, D., \& Banu, O. M. (2015). Environmental impact of carbon fibre-reinforced polymer flexural strengthening solutions of reinforced concrete beams. The International Journal of Life Cycle Assessment, 20(10), 13431358. doi:10.1007/s11367-015-0940-5

Meng, F., McKechnie, J., Turner, T., \& Pickering, S. J. (2017). Energy and environmental assessment and reuse of fluidised bed recycled carbon fibres. Composites Part A: Applied Science and Manufacturing, 100, 206-214. doi:10.1016/j.compositesa.2017.05.008

Meng, F., Olivetti, E., Zhao, Y., Chang, J. C., Pickering, S. J., \& McKechnie, J. (2018). Comparing Life Cycle Energy and Global Warming Potential of Carbon Fibre 
Composite Recycling Technologies and Waste Management Options. ACS Sustainable Chemistry \& Engineering. doi:10.1021/acssuschemeng.8b01026

Overly, J. G., Dhingra, R., Davis, G. A., \& Das, S. (2002). Environmental Evaluation of Lightweight Exterior Body Panels in New Generation Vehicles. Paper presented at the SAE International.

Røyne, F., Peñaloza, D., Sadin, G., Berlin, J., \& Svanström, M. (2015). Climate impact assessment in LCAs of forest products: Implications of method choice for results and decision-making. doi:10.1016/j.jclepro.2016.01.009

Suzuki, Hukuyama, Zushi, Origuchi, \& Takahashi. (2003). Evaluation of effects of lightening trucks on environment by LCA. Paper presented at the 2003 EcoDesign 3rd International Symposium on Environmentally Conscious Design and Inverse Manufacturing, Tokyo, Japan.

Suzuki, T., \& Takahashi, J. (2005a). LCA of Lightweight Vehicles by Using CFRP for massproduced vehicles. Paper presented at the Fifteenth International Conference on Composite Materials, Durban, South Africa.

Suzuki, T., \& Takahashi, J. (2005b). Prediction of energy intensity of carbon fiber reinforced plastics for mass-produced passenger cars. Paper presented at the Ninth Japan International SAMPE Symposium JISSE-9, Tokyo, Japan.

Witik, R. A., Payet, J., Michaud, V., Ludwig, C., Manson, J. A. E. (2011). Assessing the life cycle costs and environmental performance of lightweight materials in automobile applications. Composites Part a-Applied Science and Manufacturing, 42(11), 16941709. doi:10.1016/j.compositesa.2011.07.024

Zhou, H. (2013). The Comparative Life Cycle Assessment of Structural Retrofit Techniques. Arizona State University. SSEBE-CESEM-2013-CPR-009. 